Supporting Information

\title{
In Situ Growth of Metal-Organic Framework HKUST-1 on Graphene Oxide Nanoribbons with High Electrochemical Sensing Performance in Imatinib Determination
}

Nahid Rezvani Jalal, Tayyebeh Madrakian*, Abbas Afkhami, and Arash Ghoorchian

Faculty of Chemistry, Bu-Ali Sina University, Hamedan 6517838695, Iran

Corresponding author

*E-mail: madrakian@basu.ac.ir 


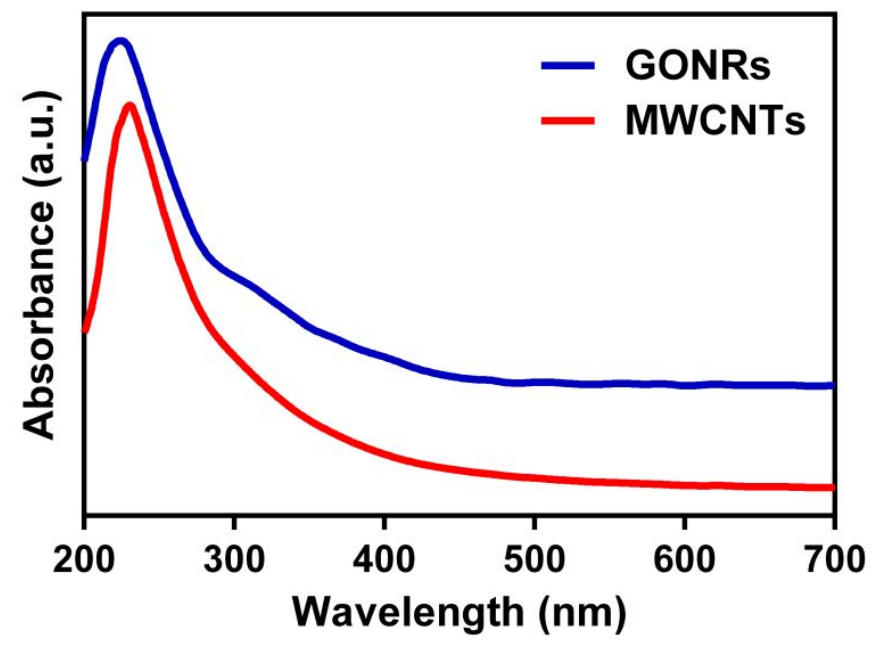

Fig. S1. UV-vis absorption spectra of GONRs and MWCNTs dispersions. 


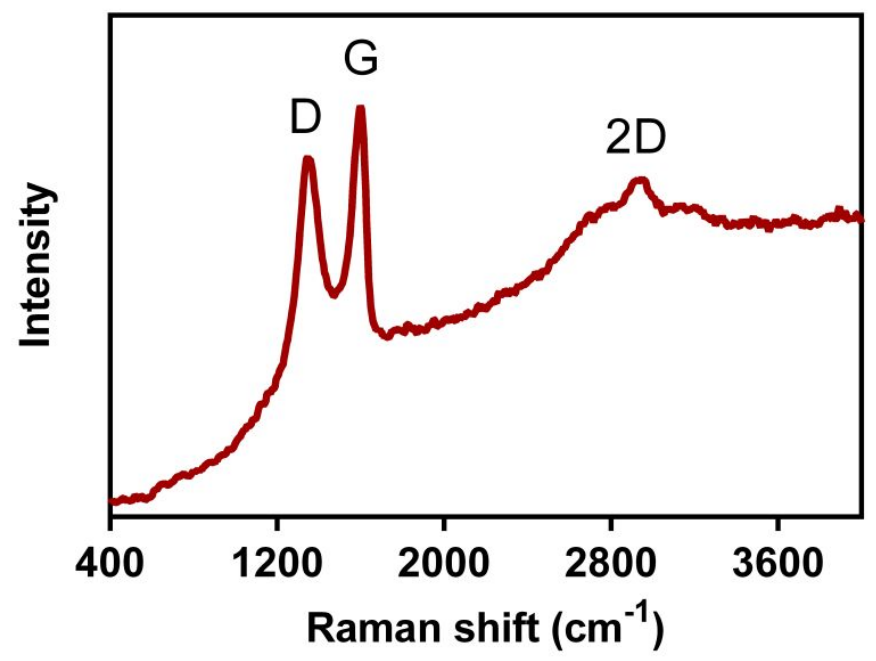

Fig. S2. Raman spectrum of GONRs. 

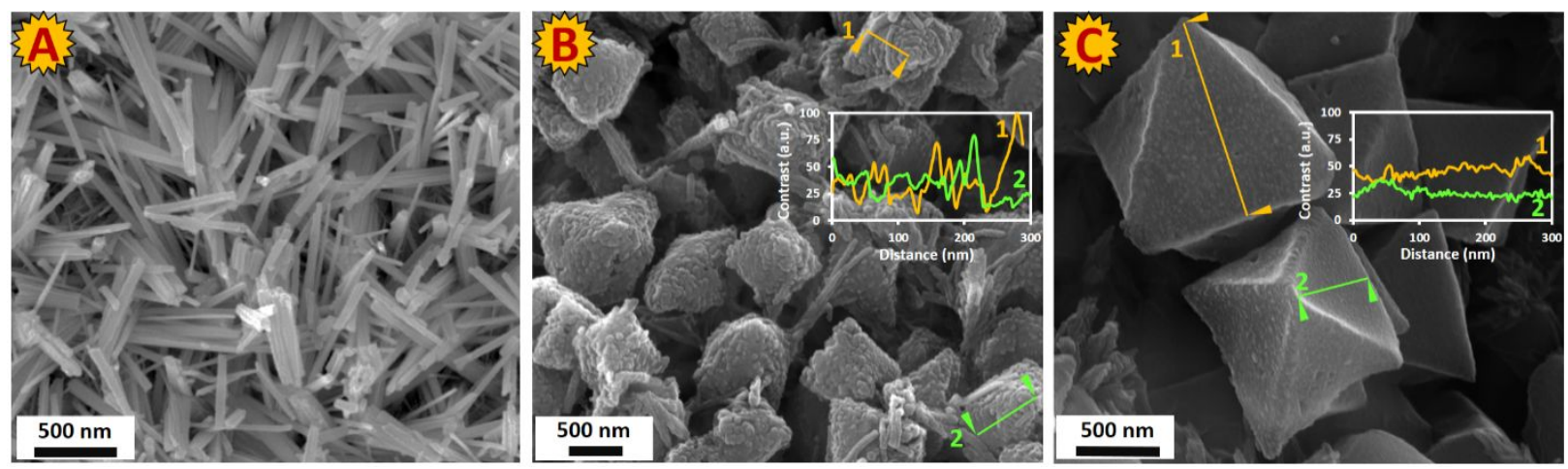

Fig. S3. The FESEM images of HKUST-1 formation from $\mathrm{Cu}(\mathrm{OH})_{2}$ NTs@GCE after A) o min, B) 0.5 min, C) 4 min remaining in ethanolic aqueous linker solution. The insets show the corresponding crosssectional profiles. 


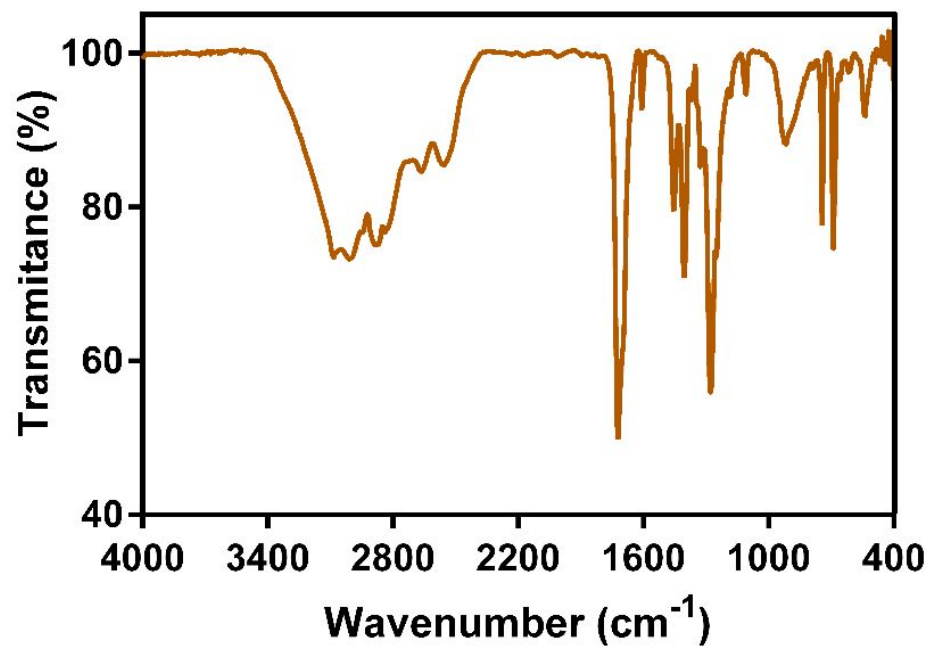

Fig. S4. FT-IR spectrum of BTC. 


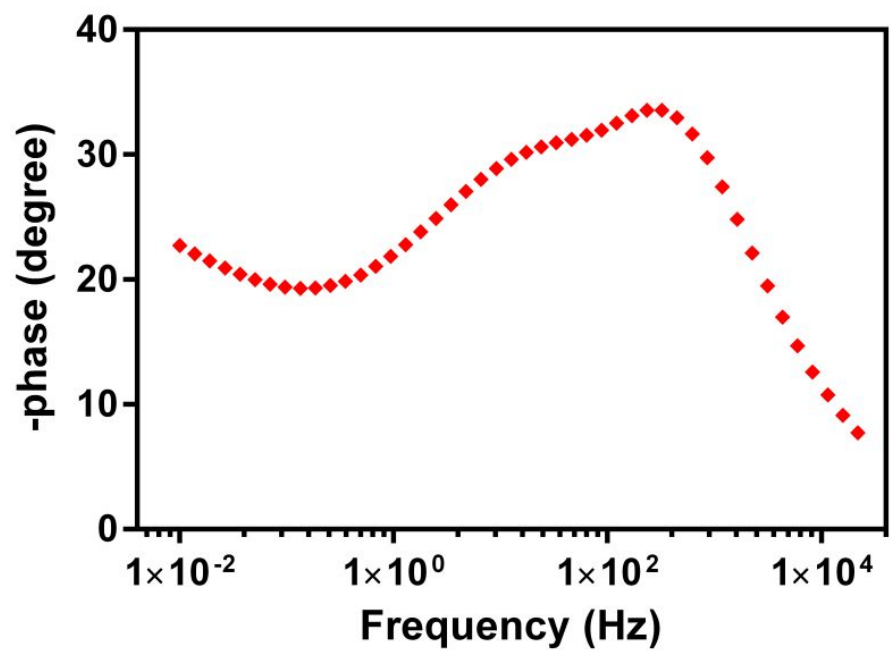

Fig. S5. Bode phase plot of HKUST-1/GONRs/GCE. 


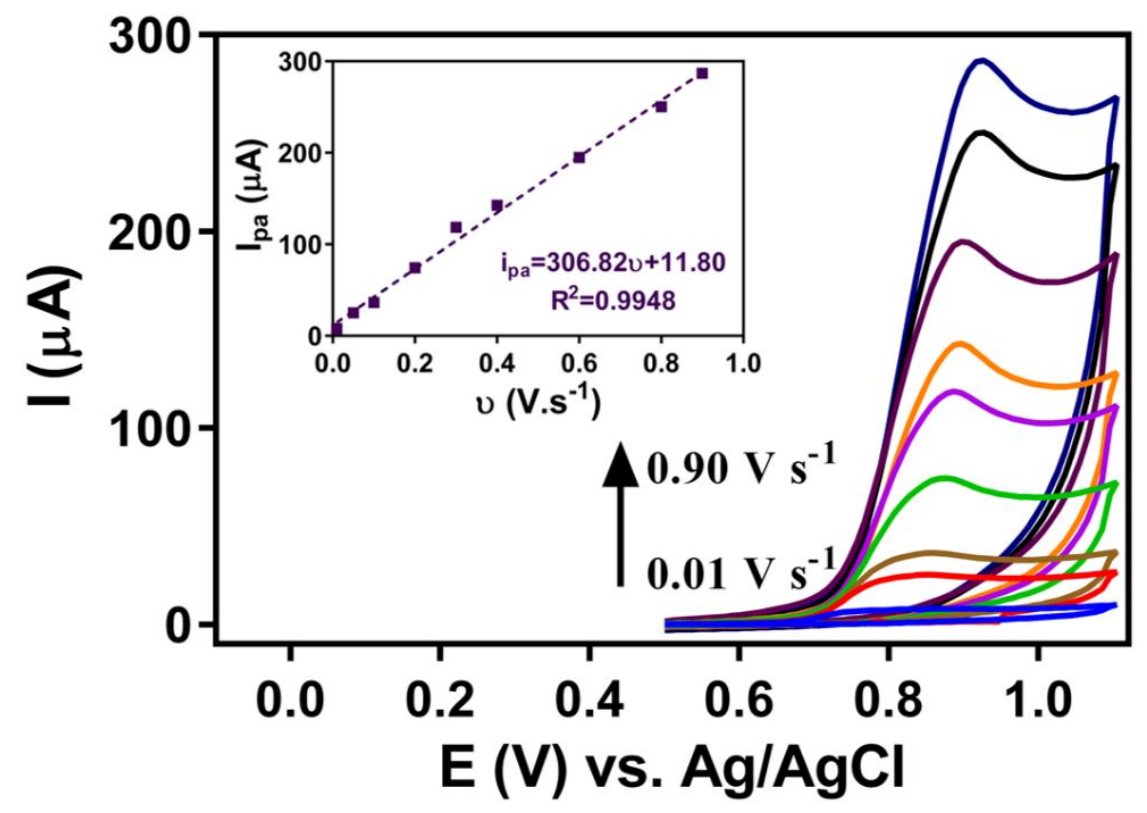

Fig. S6. Cyclic voltammograms of IMA $\left(0.15 \mu \mathrm{mol} . \mathrm{L}^{-1}\right)$ in BRB solution on HKUST-1/GONRs/GCE at different scan rates $\left(0.01-0.9 \mathrm{~V} \mathrm{~s}^{-1}\right)$. 


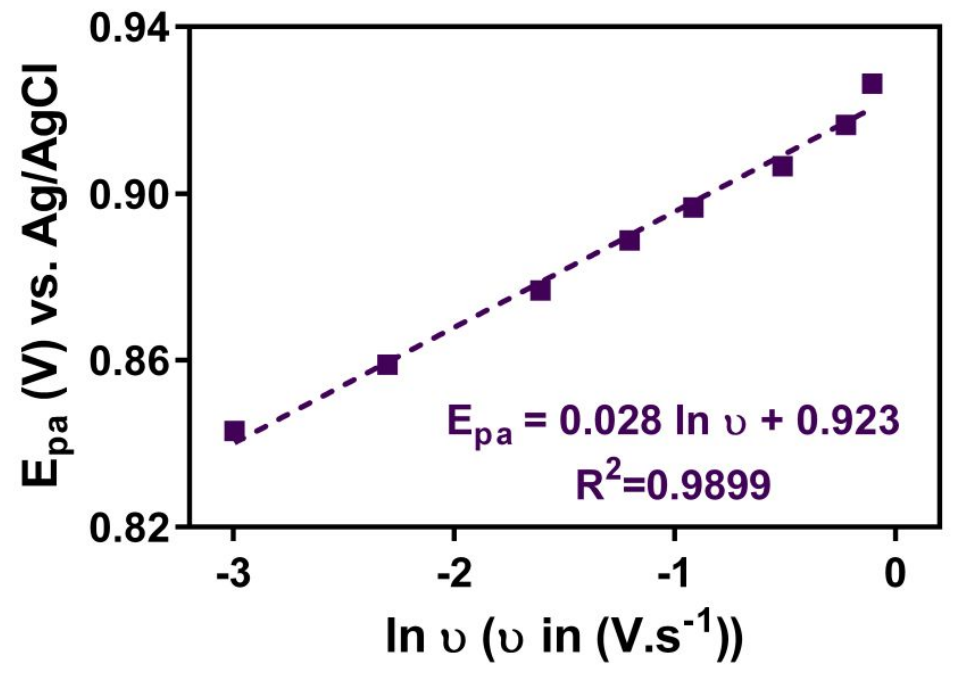

Fig. S7. The relationship between $E_{p a}$ and $\ln v$. 

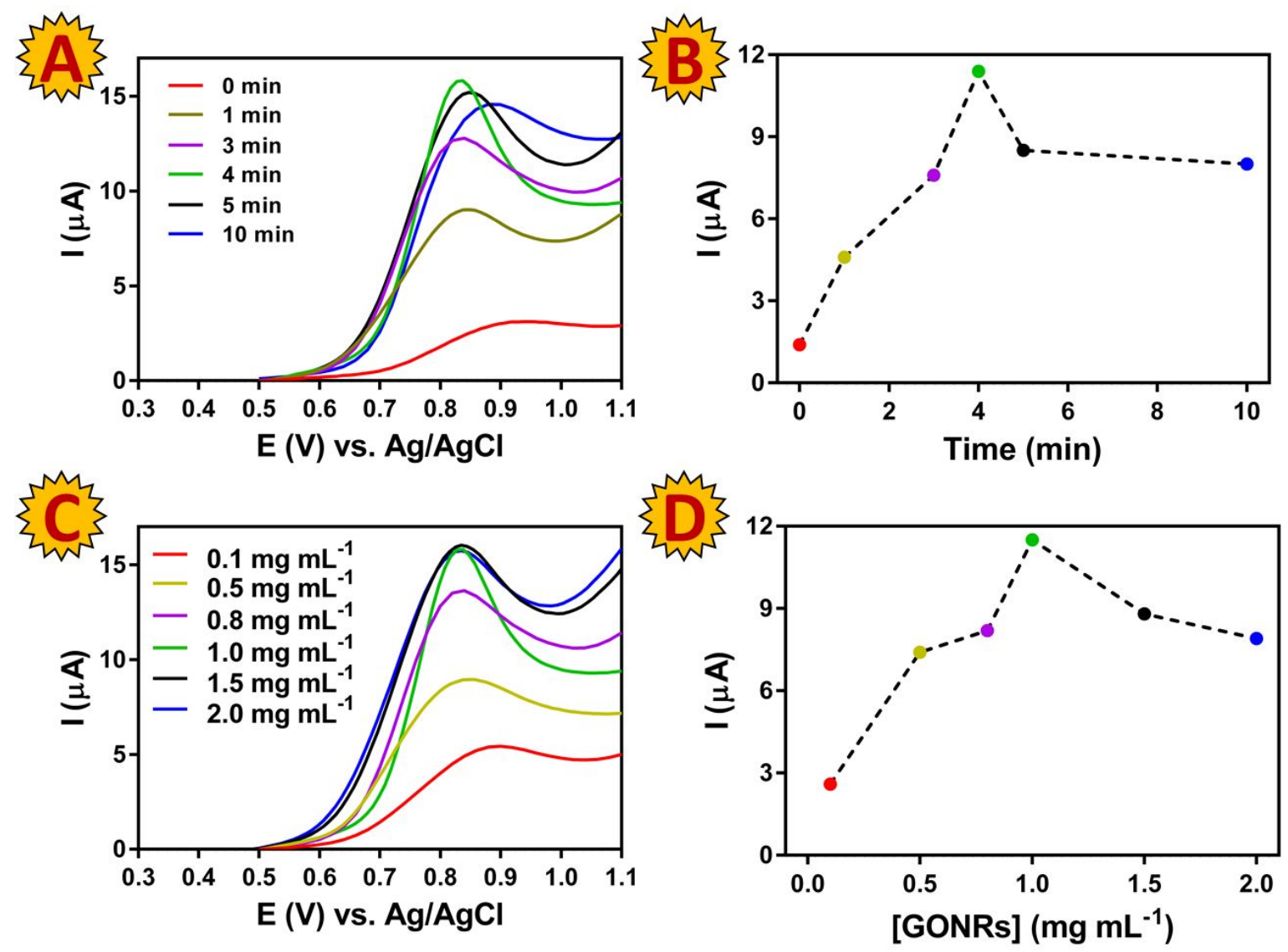

Fig. S8. The effect of reaction time in the in-situ growth of HKUST-1 (A and B) and the concentration of GONRs ( $C$ and $D$ ) on $\mathrm{I}_{\mathrm{pa}}$ for IMA oxidation onto HKUST-1/GONRs/GCE. 


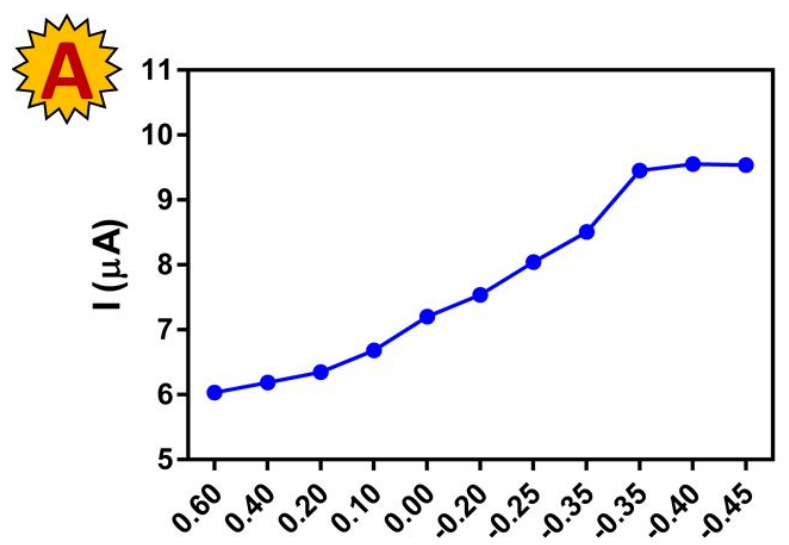

Preconcentration Potential (V)
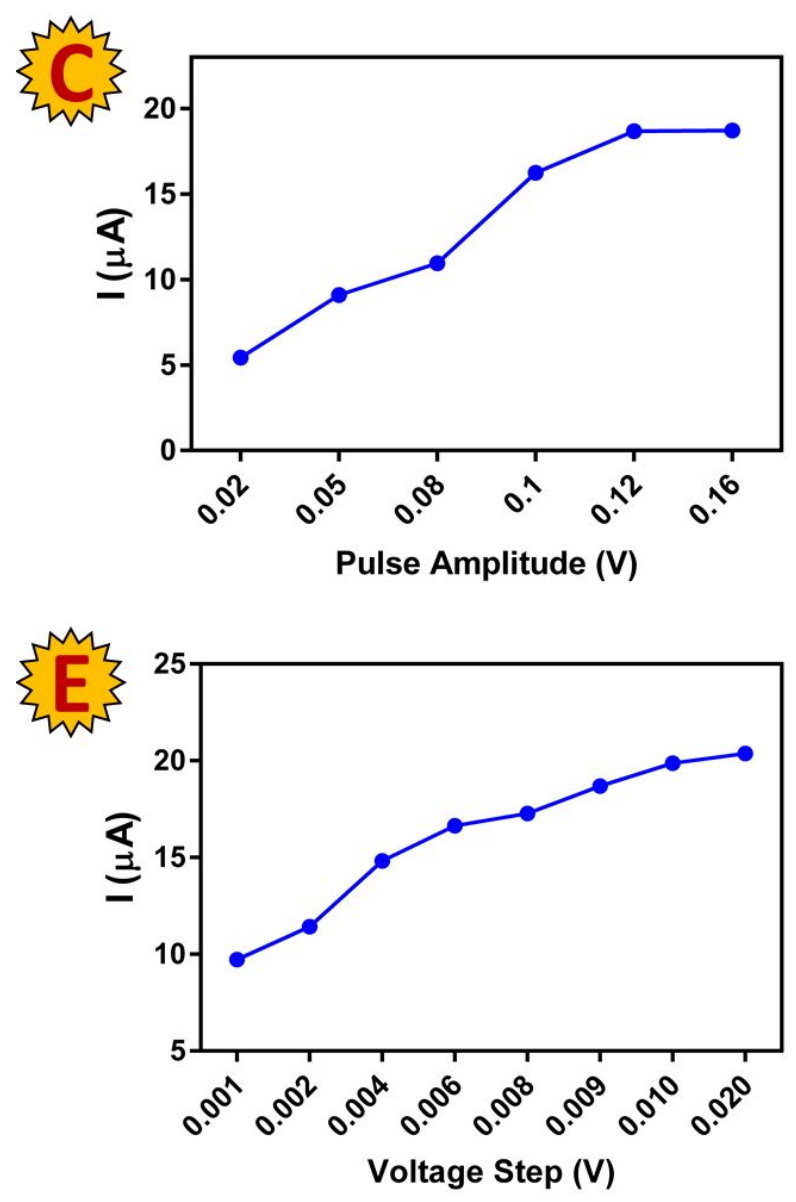

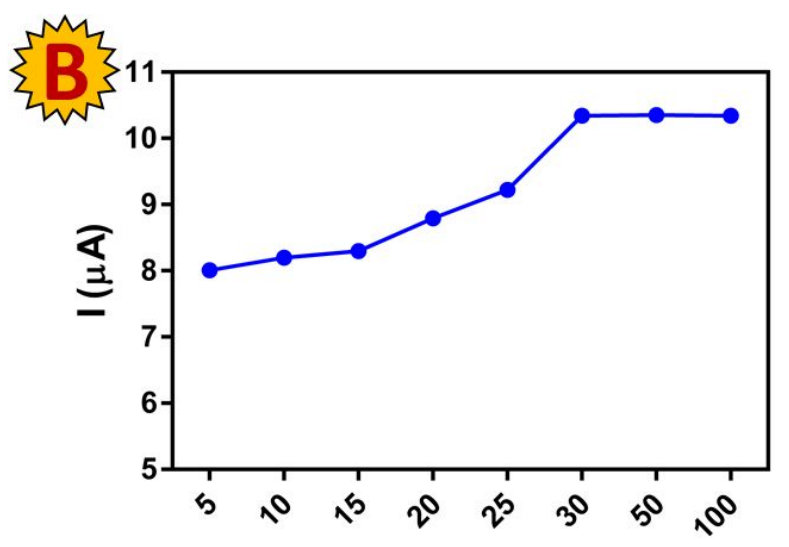

Preconcentration Time (s)

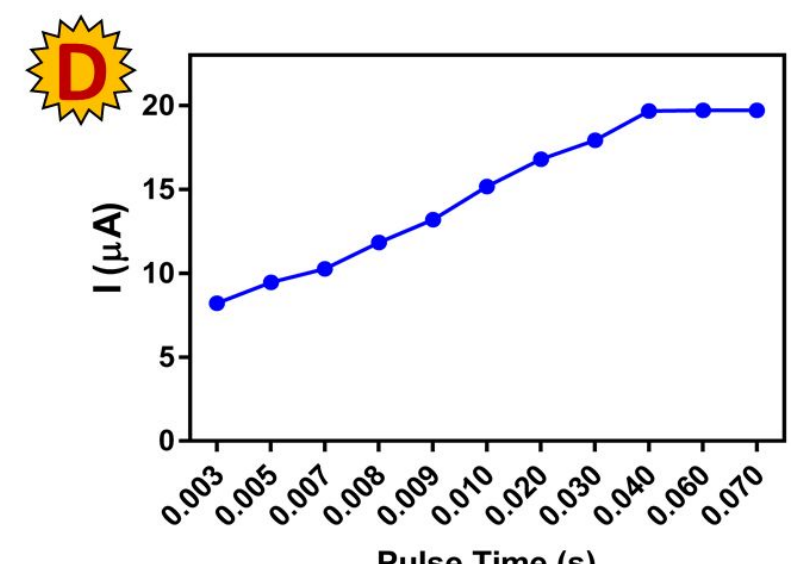

Pulse Time (s)

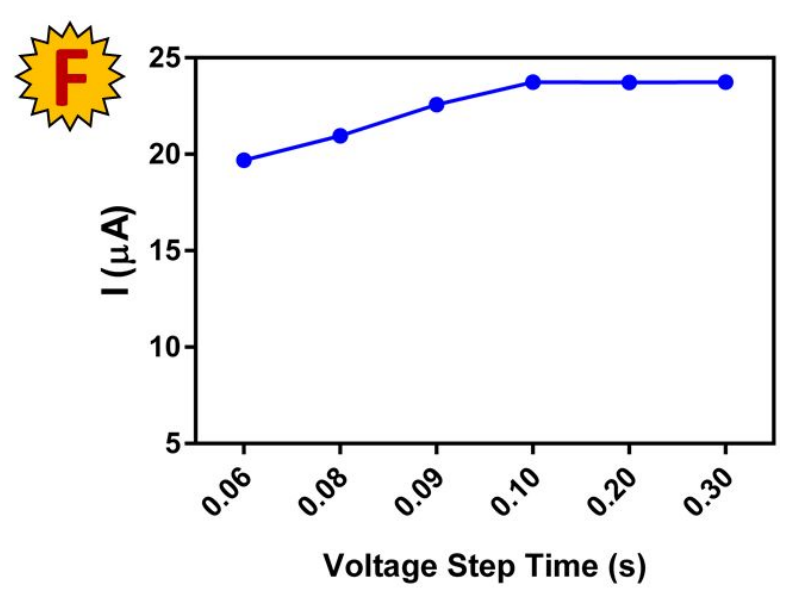

Fig. S9. The effect of (A) preconcentration potential, (B) preconcentration potential, (C) pulse amplitude, (D) pulse time, (E) voltage step and (F) voltage step time on $\mathrm{I}_{\mathrm{pa}}$ for IMA oxidation onto HKUST-1/GONRs/GCE. 
Table S1. The EIS parameters extracted from spectra of Fig. 2F obtained in different modification steps of GCE.

\begin{tabular}{ccccccccc}
\hline Electrode & $\begin{array}{c}\text { ESR } \\
(\Omega)\end{array}$ & $\begin{array}{c}\mathrm{R}_{\mathrm{ct} 1} \\
(\Omega)\end{array}$ & $\begin{array}{c}\mathrm{R}_{\mathrm{ct} 2} \\
(\Omega)\end{array}$ & $\mathrm{g}^{\mathrm{a}} 1$ & $\mathrm{~g}_{2}$ & $\begin{array}{c}\mathrm{C}_{\mathrm{dl}} \mathrm{b} \\
(\mu \mathrm{F})\end{array}$ & $\begin{array}{c}\mathrm{C}_{\mathrm{dl}} \\
(\mu \mathrm{F})\end{array}$ & $\mathrm{k}_{\mathrm{app}}\left(\mathrm{cm} \mathrm{s}^{-1}\right)$ \\
\hline GCE & 258 & 1088 & - & 0.89 & - & 0.26 & - & $1.6 \times 10^{-3}$ \\
GONRs/GCE & 244 & 72 & - & 0.93 & - & 3.04 & - & $2.3 \times 10^{-2}$ \\
HKUST-1/GCE & 297 & 1604 & - & 0.80 & - & 3.33 & - & $1.1 \times 10^{-3}$ \\
HKUST-1/GONRs/GCE & 323 & 375 & 7727 & 0.89 & 0.55 & 4.29 & 25.91 & - \\
\hline
\end{tabular}

${ }^{a}$ The constant phase element as a circuit element was obtained from: $Z=1 / Q(j \omega)^{g}$, where $Q$ is the factor of proportionality, $j$ is an imaginary number, $g$ is CPE exponent $(-1<\mathrm{g}<1)$, and $\omega=2 \pi \mathrm{f}$ is angular frequency. In the case $\mathrm{g}=-1$, CPE represents a pure inductor; $\mathrm{g}=0, \mathrm{CPE}$ is equivalent to a pure resistor; $\mathrm{g}=0.5, \mathrm{CPE}$ denotes diffusion behavior, and $\mathrm{g}=1$ indicates $\mathrm{CPE}$ is equivalent to a pure capacitor.

${ }^{\mathrm{b}}$ Double layer capacitance. 
Table S2. Interference effects of some interfering compounds for $50 \mu \mathrm{mol} . \mathrm{L}^{-1}$ IMA.

\begin{tabular}{cc}
\hline Interference & Tolerance level $\left(\mu \mathrm{mol} . \mathrm{L}^{-1}\right)$ \\
\hline $\mathrm{Na}^{+}, \mathrm{K}^{+}, \mathrm{Ca}^{2+}, \mathrm{Cl}^{-}, \mathrm{CO}_{3}{ }^{2-}$ & 10000 \\
$\mathrm{Mg}^{2+}, \mathrm{SO}_{4}{ }^{2-}$ & 1000 \\
glucose, sucrose, fructose, ascorbic acid, & 100 \\
lysine, cysteine & \\
urea & 90 \\
uric acid & 60 \\
\hline
\end{tabular}


Table S3. Recovery of IMA in real samples using HKUST-1/GONRs/GCE. $(n=3)$.

\begin{tabular}{cccc}
\hline sample & $\begin{array}{c}\text { spiked amount } \\
\left(\mu \text { mol.L }{ }^{-1}\right)\end{array}$ & $\begin{array}{c}\text { found amount } \\
\left(\mu \text { mol.L }{ }^{-1}\right)\end{array}$ & Recovery $(\%)$ \\
\hline \multirow{3}{*}{ Urine } & 0.00 & N.D. ${ }^{\text {a }}$ & \\
& 1.00 & $0.97 \pm 0.02$ & 97.0 \\
& 4.00 & $4.11 \pm 0.13$ & 102.7 \\
& 20.00 & $19.75 \pm 0.53$ & 98.8 \\
Serum & 60.00 & $60.25 \pm 1.29$ & 100.4 \\
& 0.00 & N.D. & 101.0 \\
& 1.00 & $1.01 \pm 0.03$ & 96.5 \\
& 4.00 & $3.86 \pm 0.11$ & 101.5 \\
& 20.00 & $20.30 \pm 0.78$ & 97.7 \\
\hline
\end{tabular}

a not detected 